\title{
Design and development of grader for Kagzi-lime
}

\section{S.G. PAWAR AND S.U. KHODKE}

See end of the Paper for authors' affiliation

Correspondence to :

\section{S.G. PAWAR}

Department of Agricultural Process Engineering, Vasantrao Naik Marathwada Krishi Vidyapeeth, PARBHANI (M.S.) INDIA

Email : savitapawar100@ gmail.com
-ABSTRACT : A Kagzi-lime fruit grader was developed using concentric screen principle. The machine consists of feeding, grading, collection and power transmission units. The dimensions of the machine are $1200 \mathrm{~mm}$ x $700 \mathrm{~mm}$ x $700 \mathrm{~mm}$ with a cost of approximately Rs. 25,000. The Kagzi-lime fruit were graded into three grades viz., Grade-I - above $40 \mathrm{~mm}$, Grade-II- between 40 to $36 \mathrm{~mm}$ and Grade-III- below-36 mm. The maximum grading efficiency of 95 per cent at $14 \mathrm{rpm}$ of the speed of grading unit and 7 degree feed trough angle with actual capacity was found $354.45 \mathrm{~kg} / \mathrm{h}$. and Rs. 6.62/qt cost of grading. In absence of electricity (on farm) manually operated grader is also suitable to marginal farmers with 86 per cent grading efficiency and Rs. 12.23/qt cost of grading.

— KEY WORDS : Design, Screen grader, Kagzi-lime, Cost analysis

- HOW TO CITE THIS PAPER : Pawar, S.G. and Khodke, S.U. (2016). Design and development of grader for Kagzi-lime. Internat. J. Agric. Engg., 9(1) : 12-18. 